\title{
Incontinence Pad Usage in Medical Welfare Facilities in Korea
}

\author{
Sang Hyub Lee, Ji Soon Kangำ Jeong-Wha Kim², Sun-Ju Lee \\ Department of Urology, Kyung Hee University School of Medicine, Seoul; \\ ${ }^{1}$ Department of Nursing, Kyungbok University, Pocheon; \\ ${ }^{2}$ Department of Nursing, Kyung Hee University College of Nursing Science, Seoul, Korea
}

\begin{abstract}
Purpose: The prevalence of urinary incontinence and the usage of incontinence pads by elderly residents in Korean medical welfare facilities were investigated.

Methods: From a total of 1,832 facilities, 33 medical welfare facilities in the capital area were randomly selected; all nursing homes were excluded. All data were collected by questionnaires to investigate the residents' age and sex, the presence or absence of urinary incontinence, incontinence pad usage per month, and management methods for urinary incontinence. Surveys were also conducted from January 2010 to August 2010.

Results: A total number of residents in medical welfare facilities were 2,783, and all of them were selected for this study. Approximately, $65.3 \%$ of residents (1,816 individuals) had incontinence. The mean usage was 75 incontinence pads per month. Only $15.6 \%$ of residents received proper management for urinary incontinence, while the remaining $84.4 \%$ of residents did not have any experience in evaluating or managing their urinary symptoms.

Conclusions: The prevalence of urinary incontinence in medical welfare facilities in Korea was about $65.3 \%$. However, the management of urinary incontinence was insufficient. Urologists should make further efforts for the proper management of urinary incontinence in elders in these facilities.
\end{abstract}

Keywords: Urinary incontinence; Prevalence; Geriatrics

\section{INTRODUCTION}

The population structure of South Korea has dramatically changed over the last 30 years. The proportion of the population aged 65 years or older has increased from $3.8 \%$ in 1980 to $10.7 \%$ in 2009. Considering the population ratio, South Korea is already an aging society and the elderly population proportion is expected to increase in the near future. Furthermore, the population of people aged 65 years or older is estimated to reach $25.9 \%$ in 2030 [1]. With the change in population structure, the number of elderly persons requiring medical services has also increased. Common medical problems of the elderly include osteoarthritis, hypertension, mood disorders, cardiovascular disease, dementia or memory complaints, and urinary problems [2]. These problems often occur simultaneously. Conse- quently, long-term care service for the elderly is needed in Korea. The Korean government has been making new laws and policies to reflect the needs of the aging society. In 2008, a law for long-term care for the aged was enacted and facilities for the elderly have been increasing since then. With the government's support for establishing facilities for the elderly, many elders in Korea are confined to facilities, such as sanatoriums, nursing homes, or geriatric specialized hospitals [3].

Among the common medical problems of the elderly, lower urinary tract symptoms (LUTS) such as frequency, urgency, nocturia, urinary incontinence, and urinary retention are highly prevalent. In particular, the prevalence of urinary incontinence has been increasing significantly in Korea such that the total amount spent on incontinence pads and overactive bladder medication in 2012 was about 120 billion Korean Won (KRW,
Corresponding author: Sun-Ju Lee

Department of Urology, Kyung Hee University Medical Center, Kyung Hee

University School of Medicine, 23 Kyungheedae-ro, Dongdaemun-gu, Seoul

130-872, Korea

Tel: +82-2-958-8535 / Fax: +82-2-959-6048 / E-mail: sjlee@khu.ac.kr

Submitted: October 13, 2013 / Accepted after revision: November 5, 2013
This is an Open Access article distributed under the terms of the Creative Commons Attribution Non-Commercial License (http://creativecommons.org/licenses/by-nc/3.0/) which permits unrestricted non-commercial use, distribution, and reproduction in any medium, provided the original work is properly cited. 
the currency of South Korea) and about 49 billion KRW, respectively. Urinary incontinence is troublesome, associated with mood changes in the elderly, and has an overall negative influence on the quality of life. Urinary incontinence could also diminish the quality of care received by seniors in facilities [3]. Elders with urinary incontinence in nursing homes or care facilities are more likely to have dermatological problems such as contact dermatitis, eczema, or bedsores [4]. Furthermore, urinary incontinence is expensive to manage and results in a poor hygiene status [5]. Therefore, urinary incontinence among people in these facilities is more severe than that of people who are not living in care facilities. Nevertheless, residents usually do not receive proper management for urinary problems because most of them have other problems besides LUTS, such as dementia, heart disease, or cerebral infarction. Most caregivers, families, and doctors in geriatric hospitals do not pay close attention to LUTS [4]. Consequently, many elders with incontinence in facilities spend their time with diapers or incontinence pads instead of focusing on evaluation and treatment of urinary incontinence.

Although the situation is serious, only a few investigations have been conducted to evaluate the prevalence of urinary incontinence and the amount of diaper or incontinence pad usage among the elderly in facilities. Here we evaluate the prevalence of urinary incontinence and the amount of incontinence pads used by the elderly in facilities located in the capital area of Korea (Seoul, Incheon, and Gyeonggi provinces).

\section{MATERIALS AND METHODS}

\section{Enrolled Facilities}

According to the Korean law enacted in 2008, medical welfare facilities for the aged are classified as care facilities, nursing home for seniors, and senior specialized hospitals. In 2009, a total of 1,832 facilities were registered and the total number of persons to be admitted was 81,262 . Among the registered facilities, 708 facilities in the capital area were included in this study. All nursing homes were excluded. Finally, 33 facilities were selected randomly. Total capacity of these facilities was 2,988.

\section{Data Collection and Measurement}

Urinary incontinence in this study was defined as "the complaint of any involuntary leakage of urine" [6]. Urine leakage occurring more than 3 times a day and less than 3 times a day were considered as severe incontinence and mild incontinence, respectively. Professor Sun-Ju Lee, Ji Soon Kang, and JeongWha Kim discussed the survey and questionnaire with the residents before the investigation. The questionnaire included questions regarding the resident's age, sex, educational and social status, and health conditions. We also investigated whether the residents had urinary incontinence, whether they used a catheter for emptying the urinary bladder, incontinence pad usage, and if they took any medications for urinary incontinence. In addition, pad usage for fecal incontinence was excluded from this study. The questionnaire was sent to the facilities and completed by the residents. Nurses or caregivers of the facilities filled out the questionnaires for the elderly who were not able to do so themselves.

\section{RESULTS}

\section{Characteristics of the Residents}

The number of residents who were confined to the facilities was 2,783. The mean age of the residents was 82.7 years. The percentage of elders aged 89 years or older was $44.7 \%$. The percentages of residents aged $84-88$ years, $78-83$ years, and $\leq 77$ years were $37.8 \%, 15.1 \%$, and $2.4 \%$, respectively. We observed that residents were confined to the facilities owing to dementia (45.9\%) and cerebral infarction (15.7\%). The proportion of residents who were diagnosed with Parkinson disease was 3.6\%. Residents were admitted because of cerebral hemorrhage (2.4\%), spinal cord injury (1.5\%), or owing to multiple diseases (30.8\%) (Table 1).

\section{Prevalence and Severity of Urinary Incontinence and Incontinence Pad Usage}

The number of elderly persons who experienced urinary incontinence was 1,816 (65.3\%). Approximately $91.7 \%$ of the women and only $8.3 \%$ of the men had urinary incontinence. Severe symptoms were present in $64 \%$ of residents with incontinence. In all severe cases of incontinence, urine leakage occurred more than 3 times a day. About $26 \%$ of the residents experienced urinary incontinence once or twice a day. We observed that 3.3\% of residents had 2 or 3 leakages per week and only $1.5 \%$ of the elderly persons experienced a leakage once or twice a week. The total amount of incontinence pads used by residents with incontinence was 131,107 per month. An average of 75.5 pads was used by each resident with incontinence. Consequently, residents with urinary incontinence were spending an average of 50,000 or 60,000 KRW per month (Table 2). 
Table 1. Characteristics of the residents

\begin{tabular}{lc}
\hline Characteristic & Value \\
\hline No. of residents (\%) & $2,783(100)$ \\
Gender, $\mathrm{n}(\%)$ & $795(28.6)$ \\
Male & $1,988(71.4)$ \\
Female & 82.7 \\
Mean age (yr) & \\
Age classification $(\mathrm{yr})$ & $2.4 \%$ \\
$\leq 77$ & $15.1 \%$ \\
$78-83$ & $37.8 \%$ \\
$84-88$ & $44.7 \%$ \\
$\geq 89$ & \\
Reason of admission & $45.9 \%$ \\
Dementia & $15.7 \%$ \\
Cerebral infarction & $3.6 \%$ \\
Parkinson disease & $2.4 \%$ \\
Cerebral hemorrhage & $1.5 \%$ \\
Spinal cord injury & $30.8 \%$ \\
Other diseases & \\
\hline
\end{tabular}

\section{Management of Urinary Incontinence}

Most patients with incontinence did not receive proper treatment and used incontinence pads for symptom management. Only $15.6 \%$ of the elderly with incontinence had proper treatment, such as oral medications for relieving urinary symptoms or catheter drainage of urine (Fig. 1). Approximately $6.6 \%$ of residents had indwelling Foley catheters. Suprapubic catheters were not used.

\section{DISCUSSION}

According to an investigation from the United States (US) in 2000, about 17 million community-dwelling adults had urinary incontinence and an estimated 33 million had an overactive bladder. Consequently, it costs up to 32 billion US dollars annually because of overactive bladder symptoms [7]. A detailed report similar to the investigation from US has not yet been reported in Korea. According to the press release, the total cost of incontinence pads in 2012 was about 120 billion KRW. On the basis of data from IMS Health Korea Ltd. (Seoul, Korea), a healthcare information company, the total cost of overactive bladder medication was about 46 billion KRW in 2012. However, these data are not from the investigation of health profes-
Table 2. Prevalence and severity of urinary incontinence \& usage of incontinence pad

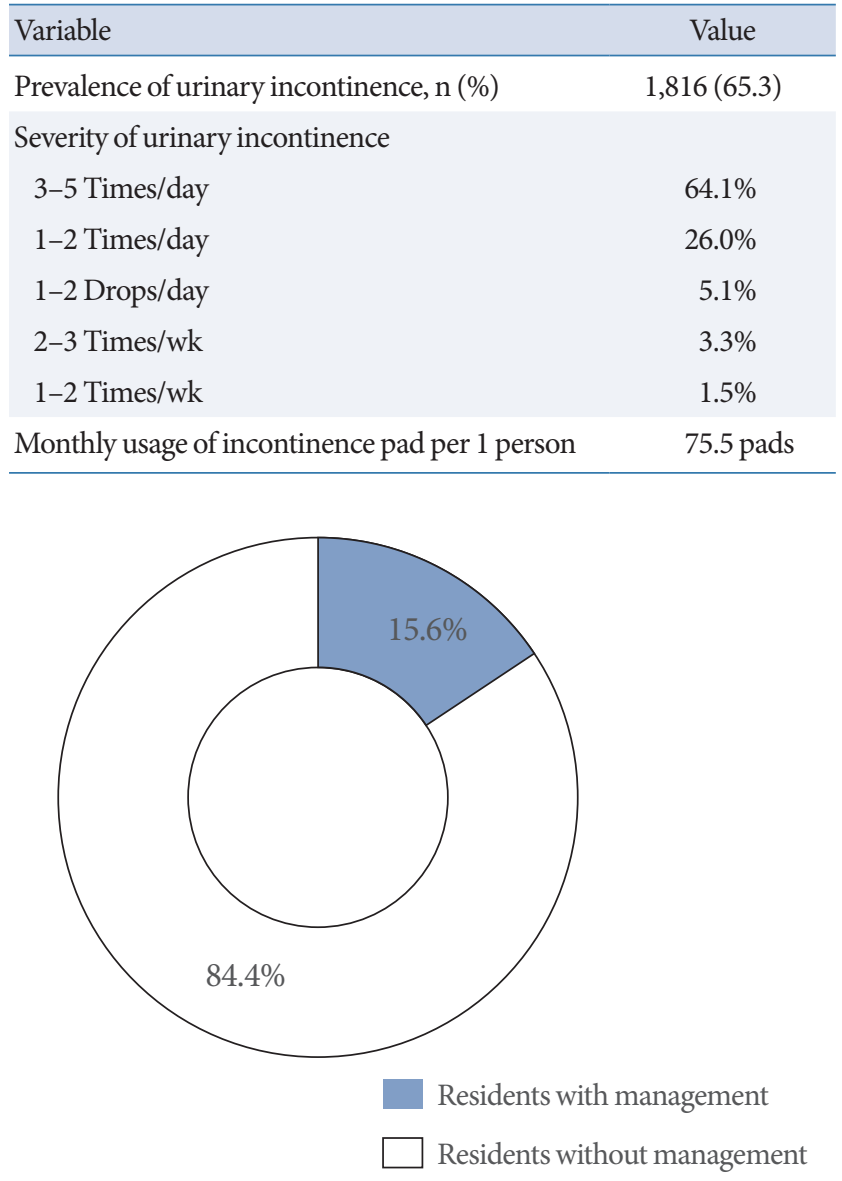

Fig. 1. Management of urinary incontinence.

sional but from the press so they are not accurate. Definitive and further investigations are needed to accurately evaluate the social expenses for urinary incontinence in Korea.

It is very difficult to obtain accurate data for urinary incontinence, because different surveying methods were used in different studies and a variety of ideas about the definition of urinary incontinence exists among people from different social and cultural backgrounds [8]. In the present study, urinary incontinence was evaluated as "the complaint of any involuntary leakage of urine," which was defined by the International Continence Society in 2002 [6]. According to this definition, about $65 \%$ of the elderly population in the facilities experienced urinary incontinence. The prevalence of urinary incontinence determined by our study is higher than that of other studies from Korea. Oh et al. [8] reported that the prevalence of urinary incontinence in Korea was about 41.2\%. However, Oh et al. [8] 
investigated the prevalence of urinary incontinence among Korean women aged 30-79 years, which may explain the difference in prevalence rates between this study and our investigation. Furthermore, Shin et al. [4] reported that $48 \%$ of residents at a sanatorium in Busan had urinary incontinence. The prevalence rate reported by that study is lower than that observed in our study because Shin et al. [4] surveyed the residents using a different definition of urinary incontinence. Compared with our report, the study from the US in 2009 revealed that the overall prevalence of urinary incontinence in nursing home residents ranged $43-77 \%$, with a median of $58 \%$ [6].

Only $15.6 \%$ of residents with incontinence received proper management of urinary incontinence. About $7 \%$ of them had a Foley catheter and others took anticholinergic agents to manage urinary incontinence. An estimated $84.4 \%$ of residents with incontinence managed their condition by using only incontinence pads. These results are similar to the study from Busan, which reported that $74.8 \%$ of residents used only diapers for the management of urinary incontinence, $8.7 \%$ of them had a catheter, and only $7.5 \%$ were prescribed anticholinergic agents. The Busan study concluded that most patients used diapers, because it is more convenient, and most of them were also suspected to have fecal incontinence [4]. Although residents with fecal incontinence were excluded in our study, many residents used only incontinence pads. The situation may be caused by not only caregiver's thought that diaper use for incontinence might reduce the costs for incontinence care but also indifference of medical attendances. Diaper use for incontinence maybe influenced by the wrong thought that the overall cost of diaper use is less than that of medication for incontinence and personal opinions held by medical professionals.

Wearing diapers can cause mental or physical stress to residents. Shin et al. [4] reported that $28 \%$ of the elderly in sanatoriums who used diapers had dermatologic diseases at the perineal and inguinal area, such as eczema or bedsores. Shin et al. [4] have indicated that these problems are a result of improperly managing urinary incontinence and the lack of hygienic care.

Most Western countries have become an aged society since the 1980s and have faced similar issues regarding elderly persons with incontinence who are in facilities [9]. Therefore, many studies have been conducted to evaluate the problems of residents with incontinence and to find possible solutions to these problems. In the past, many nursing homes in the US did not provide sufficient care for patients with urinary incontinence [10]. In 1988, caring for incontinence in a nursing home cost an estimated 1.1 billion US dollars per year, which represented 3-4\% of all Medicaid payments made to nursing homes [11]. A study from Canada has proven that a proper management approach to urinary incontinence could lower laundry and supply costs. Moreover, nursing time also reduced with appropriate management of urinary incontinence [12]. Another study revealed that an individualized program could not only improve activity of daily living, but also reduce urinary incontinence [13]. Furthermore, bladder training, such as prompted voiding, was proven to be helpful for elders with incontinence [14].

A limitation of our study was that only 33 facilities in the capital area were enrolled. Therefore, not all facilities in Korea were represented. Nevertheless, we were able to show that many seniors in facilities have urinary incontinence. However, a systematic and proper management for urinary incontinence is lacking in these facilities. Therefore, it is necessary to make a thorough investigation into the prevalence of urinary incontinence among the residents in Korean facilities. Urologists must also provide proper management programs based on these investigations to improve the quality of life for residents with incontinence.

\section{CONFLICT OF INTEREST}

This study was funded and supported by Jeil Pharmaceutical Co., Korea.

\section{REFERENCES}

1. Kim N. Long-term care services expenditure projection in South Korea from 2015 to 2050. Int J Health Plann Manage 2013 Jul 13 [Epub]. http://dx.doi.org/10.1002/hpm.2204.

2. Lam R, Gallinaro A, Adleman J. Medical problems referred to a care of the elderly physician: insight for future geriatrics CME. Can Geriatr J 2013;16:114-9.

3. Yoon JY, Lee JY, Bowers BJ, Zimmerman DR. The impact of organizational factors on the urinary incontinence care quality in longterm care hospitals: a longitudinal correlational study. Int J Nurs Stud 2012;49:1544-51.

4. Shin CW, Kim SD, Cho WY. The prevalence and management of urinary incontinence in elderly patients at sanatorium in Busan area. Korean J Urol 2009;50:450-6.

5. Offermans MP, Du Moulin MF, Hamers JP, Dassen T, Halfens RJ. Prevalence of urinary incontinence and associated risk factors in 
nursing home residents: a systematic review. Neurourol Urodyn 2009;28:288-94.

6. Abrams P, Cardozo L, Fall M, Griffiths D, Rosier P, Ulmsten U, et al. The standardisation of terminology of lower urinary tract function: report from the Standardisation Sub-committee of the International Continence Society. Neurourol Urodyn 2002;21:167-78.

7. Levy R, Muller N. Urinary incontinence: economic burden and new choices in pharmaceutical treatment. Adv Ther 2006;23:556-73.

8. Oh SJ, Park WH, Park CH, Paick JS, Seo JT, Lee YS, et al. Prevalence of urinary incontinence and incontinence-related quality of life in korean women: a population-based study. J Korean Continence Soc 2003;7:73-80.

9. Pinkowski PS. Urinary incontinence in the long-term care facility. J
Wound Ostomy Continence Nurs 1996;23:309-13.

10. Flitter MA. Neurometrics. JAMA 1982;248:1308-9.

11. Cella $M$. The nursing costs of urinary incontinence in a nursing home population. Nurs Clin North Am 1988;23:159-68.

12. Borrie MJ, Davidson HA. Incontinence in institutions: costs and contributing factors. CMAJ 1992;147:322-8.

13. Vinsnes AG, Helbostad JL, Nyronning S, Harkless GE, Granbo R, Seim A. Effect of physical training on urinary incontinence: a randomized parallel group trial in nursing homes. Clin Interv Aging 2012;7:45-50.

14. Pinkowski PS. Prompted voiding in the long-term care facility. J Wound Ostomy Continence Nurs 1996;23:110-4. 